\title{
Crisis, desempleo y salud
}

Tomando una frase de uno de nuestros buenos comentaristas y narradores deportivos de la televisión, podemos decir que ¡El rancho cogió candela!

Me estoy refiriendo al rancho del capitalismo neoliberal globalizado, la más agresiva y dañina de las distintas versiones de esta formación económico-social. Agresividad exacerbada bajo el liderazgo de su último gran jefe visible, G. W. Bush, quien condujo magistralmente el sistema al desastre. Muchos continúan Ilamando Gran Crisis a la de los años 1929 y subsiguientes. Con lo que ya sabemos de la crisis actual, esta es mayor. Se ha instalado más rápidamente en el centro del poder capitalista, se ha extendido a velocidad propia de los medios de comunicación electrónica, dejó paralizados en momentos críticos a los que debían actuar para ralentizar o atenuar sus efectos: G. W. Bush, el Fondo Monetario Internacional (FMI), el Banco Mundial (BM), los bancos de la Unión Europea (UE), los "tanques pensantes" que trabajan detrás del líder. Tal vez porque todos son culpables e ignorantes que creyeron que había llegado el fin de la historia. Son los que creyeron que el mercado, del que alguien con razón ha dicho que es ciego, era el gran e infalible regulador económico y social.

Hace ya bastante tiempo, Carlos Marx dejó sentado que las crisis del sistema capitalista son algo inherente al mismo, períodos obligados del sistema, y que son cíclicas. De qué sorprendernos entonces, al menos de qué sorprendernos los revolucionarios que hemos leído a Marx. Entre nosotros, nuestro líder político Fidel, y uno de nuestros más brillantes economistas, Osvaldo Martínez, lo habían advertido desde hace tiempo. Por esto considero que estamos en mejores condiciones de resistir los embates que ya están llegando. La experiencia del "período especial" es ilustrativa. Resistimos una caída del PIB de 33,4 \% entre 1991 y 1995, y entre los años 1991 a 1994 el gasto público en salud pública creció de 924, 9 a 1 061,1 millones de pesos. ${ }^{1}$ No se cerró un aula, no se dejó de pagar a un jubilado... Pero volvamos a la crisis. Tiene la peculiaridad, que la diferencia mucho de la anterior, de ser una crisis no sólo financiera o bursátil, sino, podríamos decir, integral. A lo financiero se agrega la crisis energética, la alimentaria, la del ambiente y la que se deriva de los cambios climáticos, la de las migraciones masivas, la del consumo de drogas ilícitas y el auge del narcotráfico, la de la salud. De todo esto, lo más dramático en sus consecuencias negativas inmediatas para la salud humana es "la explosión del desempleo", que expone Ramonet en estos términos: 
Causa de pobreza, de angustia y de exclusión, la lepra del desempleo se extiende. En Estados Unidos la recesión ha destruido 3,6 millones de puestos de trabajo a un ritmo nunca visto. La mitad durante los últimos tres meses. El total de parados asciende a 11,6 millones... En la India entre octubre y diciembre de 2008 medio millón de puestos de trabajo se destruyeron... En España, durante el pasado mes de enero, el número de despidos aumentó en casi 200000 personas y el total de desocupados sobrepasa ya los 3 320, 000 ... Más de 827000 hogares cuentan con todos sus miembros desempleados... El Director General de la Organización Internacional del Trabajo (OIT), Juan Somavia, estima que el número de desempleados en el mundo ( 190 millones en 2008) podrían incrementarse en 51 millones más a lo largo de 2009. ${ }^{2}$

Y concluye Ramonet:

Para los ciudadanos, el desempleo es una de las peores formas de represión, una demostración en carne propia de la violencia del capitalismo. Por eso la rabia. Se avecinan tiempos sombríos. El concepto de crisis no alcanza a explicar el momento que estamos viviendo. Un cambio de era. Una mutación de valores. ¿Una esperanza de justicia y de progreso ${ }^{2}$

En este último párrafo pueden encontrarse elementos de verdad, pero me permito recordar que el capitalismo no se caerá, no se autodestruirá, no desaparecerá debido a sus crisis; al capitalismo es necesario atacarlo para tumbarlo, para aplastarlo. Será acción de masas conducidas por las vanguardias revolucionarias, fortalecidas por la necesaria batalla de ideas. Hoy en América Latina se vislumbra esa lucha.

Entre las crisis que se han enumerado se incluyó la de la salud. Al respecto, la Directora General de la Organización Mundial de la Salud, Margaret Chan, ha declarado que:

Los países de todos los niveles de desarrollo económico están preocupados por el impacto de la crisis financiera en la salud. Si continúa aumentando el desempleo, si fallan las redes de protección social, si se erosionan los ahorros y los fondos de pensiones y si caen los gastos públicos, es inevitable que la salud de la gente sufra. Y añade: El impacto es directo cuando el estrés causa un aumento del las enfermedades mentales y el uso del tabaco, el alcohol y otras sustancias dañinas. Y todo empeora cuando los servicios sanitarios no pueden mantener los cuidados que necesitan los enfermos ${ }^{3}$

La Dra. Chan esboza algunas acciones que deben desplegarse al respecto. Primero, denunciar los problemas de modo inequívoco. Sí, siempre denunciar, tanto las atrocidades de ciertos regímenes como la corrupción de algunas personas, ha sido un arma eficaz en la lucha por las conquistas sociales, entre ellas la salud del pueblo. En Cuba han abundando ejemplos, el médico Gustavo Aldereguía, el político Eduardo Chivas, el periodista Mario Kuchilán, el poeta Nicolás Guillén, y el más certero y eficaz en este arte, Fidel Castro. Estos nos convocan a denunciar los manejos privatizadores de los servicios estatales de salud, a condenar los abusos de las transnacionales de la industria farmacéutica, a combatir las migraciones masivas de personal de salud de los países pobres a los ricos. Sobre esto y más se ha tratado en el reciente Encuentro Internacional de Economistas sobre Globalización y Problemas del Desarrollo que tuvo lugar en La Habana entre los días 2 y el 6 de marzo de 2009. Muchas y sólidas denuncias se hicieron allí. 
También se propone la planificación de contingencias basadas en información de alta calidad. Esto es una posición tecnocrática. El problema esencial, sin embargo, es de naturaleza política y la defensa de los más vulnerables ha de estar en el centro de la estrategia para encararlo. Por supuesto que se necesita información, y esta, si no es de calidad, no debe utilizarse. También el análisis interdisciplinario (puede añadirse el intersectorial), pero se menciona recurrir a expertos de la Organización Mundial de Comercio (OMC), esto sería "meter el diablo en casa", como lo sería también convocar a los expertos del FMI.

Se recomienda algo que juzgo indispensable: el sostenimiento del gasto público. Es necesario garantizar que los gastos ayuden a los más pobres. Sólo así alcanzarán a tener un mejor efecto sobre la salud de la población.

El acento debe ponerse en la defensa, incluso, del desarrollo de la atención primaria de salud. Es lo más eficiente, es lo más eficaz. La renovación de la atención primaria de salud, que propone la Organización Panamericana de la Salud, debe respaldarse en cada país de Las Américas con alta prioridad.

Se puede afirmar que, como defensa contra las crisis, es necesaria la denuncia firme de las maniobras neoliberales, la oposición a la tecnocracia y a los expertos alineados con el FMI, la defensa del gasto público en salud, orientado principalmente a la atención primaria, y el otorgamiento de la prioridad a la atención a la población más vulnerable. El enfoque deberá ser, en cada caso, político y social, procurando que se vincule a los grupos sociales afines, e incluso gestando alianzas entre países cuyos gobernantes compartan ideas progresistas.

Francisco Rojas Ochoa

\section{REFERENCI AS BI BLI OGRÁFI CAS}

1. Rojas Ochoa F, López Pardo C. Economy, Politics, and Health Status in Cuba. Inter J Health Services. 1997; 27(4): 791-807.

2. Ramonet I. La explosión del desempleo. Le Monde diplomatique, marzo de 2009. No. 161, p. 1. [Edición española].

3. Chan N. Estado de alarma en la salud pública mundial. Granma, viernes 13 de marzo de 2009, p. 9. 